\title{
A mortalidade por caussas violentas no Estado e nas Mierorregĩ̄es de Santa Catarina
}

\section{The mortality by violent deaths in Santa Catarina State and its Microrregions}

\author{
Sonia Hess*
}

Recebido: 09/10/2017. Aprovado: 23/11/2017.

\begin{abstract}
Resumo: Em Santa Catarina, entre 2011 e 2015, as causas violentas corresponderam à terceira principal causa de óbito dos homens, e à quinta causa de morte entre as mulheres, totalizando 16.873 óbitos masculinos e 4.401 femininos. Dentre os homens, as principais causas de morte foram os acidentes de transporte (7.346), as agressões (3.695), as outras causas externas de lesões acidentais (3.179) e o suicídio (2.205). Entre as mulheres, foram 1.827 mortes por acidentes de transporte, 1.275 por outras causas externas de lesões acidentais, 655 por suicídio e 488 por agressões. Com relação ao suicídio, para ambos os sexos, as taxas de mortalidade a cada 100 mil habitantes registradas no Estado foram mais de $50 \%$ superiores àquelas aferidas no país. Entretanto, as taxas de mortalidade por agressões foram inferiores à média nacional para ambos os sexos, enquanto que as taxas de mortalidade por acidentes de transporte foram mais de $20 \%$ superiores às registradas no país, para ambos os sexos.
\end{abstract}

Palavras-chave: Suicídio. Acidentes de Transporte. Agressões.

Abstract: In the state of Santa Catarina, Brazil, between 2011 and 2015, 16,873 men and 4,401 women died from violent deaths. Those numbers correspond to the third main cause of deaths for men and the fifth for women. Among the men, the main causes of death were traffic accident $(7,346)$, physical violence $(3,695)$, accidental injuries $(3,179)$ and suicide $(2,205)$. Among women, there were 1,827 deaths from traffic accident, 1,275 from accidental injuries, 655 from suicide and 488 from physical violence. With regard to suicide, for both genders, the mortality rates for every 100 thousand inhabitants registered in the Santa Catarina state

* Pós-Doutora em Química (UNICAMP, Campinas, 1997; Università Cattolica del Sacro Cuore, Roma, 1997; UFSC, Florianópolis, 2010). Doutora em Química (UFSC, Florianópolis, 1995). Mestra em Química (UFSC, Florianópolis, 1989). Graduada em Engenharia Química (UFSC, Florianópolis, 1985). Professora do Campus de Curitibanos da Universidade Federal de Santa Catarina (UFSC).

E-mail: soniahess@gmail.com 
were more than $50 \%$ higher than those measured in the whole country. However, the mortality rates from physical violence were lower than he national average for both genders and the while mortality rates due to traffic accidents were more than 20\% higher than those recorded in Brazil for both genders.

Keywords: Suicide. Traffic Accidents. Physical Violence.

\section{Introdução}

O objetivo do presente artigo é apresentar, de forma resumida, os dados da mortalidade por causas violentas no Brasil e, de maneira mais abrangente, no Estado de Santa Catarina e suas microrregiões. Espera-se que as informações possam ser úteis à formulação de políticas públicas e à mobilização da sociedade na busca por medidas eficazes para a minimização dos índices de violência levantados.

De acordo com os dados de mortalidade disponibilizados pelo Ministério da Saúde, no Sistema de Informações de Mortalidade, nos cinco anos compreendidos entre 2011 e 2015, no Brasil, 758.616 pessoas perderam a vida em decorrência da violência (causas externas). Os homens constituíram a maioria $(82 \%)$ das vítimas, totalizando 623.912 óbitos no período, e as mulheres, 133.859 óbitos ${ }^{1}$. Tais dados revelam que, no país, a violência tem resultado em número de vítimas muito superior àquele verificado em conflitos recentes, como o da guerra da Bósnia, que resultou em 176.000 mortos, de 1991 a $1995^{2}$.

Nas Figuras 1 e 2 são apresentados os números totais de óbitos no Brasil, no período de 2011 a 2015, segundo as causas descritas nos Capítulos do Código Internacional de Doenças (CID-10), para os sexos masculino e feminino, respectivamente. Naquele período, as causas externas (Capítulo XX) representaram a segunda principal causa de óbito de homens e a sexta causa da morte de mulheres, no país (SIM/MS, 2017).

1 BRASIL. MINISTÉRIO DA SAÚDE. SISTEMA DE INFORMAÇÕES SOBRE MORTALIDADE - SIM/MS. Disponível em: <http://tabnet.datasus.gov.br/cgi/deftohtm.exe?sim/ cnv/ext10uf.def>. Acesso em: nov. 2017. As próximas referências a essa fonte serão indicadas no próprio texto do seguinte modo: (SIM/MS, 2017).

2 Obermeyer, Z.; Murray, C. J. L.; Gakidou, E. Fifty years of violent war deaths from Vietnam to Bosnia: analysis of data from the world health survey programme. British Med. J., v. 336, n. 7659, p. 1482-1486, 2008. 
Figura 1 - Número de óbitos registrados no Brasil, segundo as causas (Capítulo CID), 2011 a 2015, sexo masculino.

NÚMERO DE ÓBITOS NO BRASIL SEGUNDO CAUSAS (CAPÍTULO CID-10), 2011-2015, SEXO MASCULINO

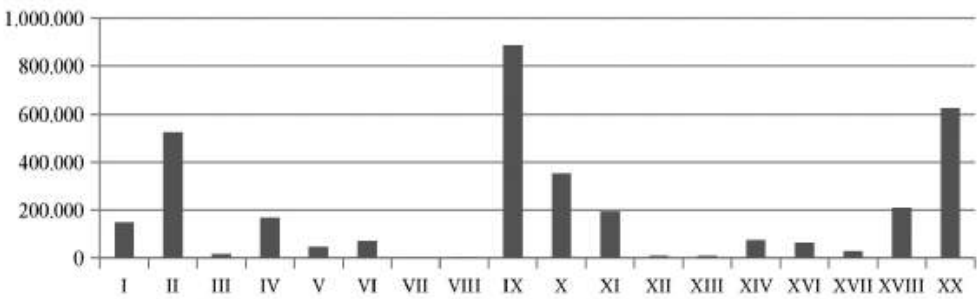

Causas de óbito segundo o Código Internacional de Doenças, CID-10: Capítulo I, algumas doenças infecciosas e parasitárias; Cap. II, neoplasias (tumores); Cap. III, doenças do sangue, órgãos hematopoiéticos e transtornos imunitários; Cap. IV, doenças endócrinas nutricionais e metabólicas; Cap. V, transtornos mentais e comportamentais; Cap. VI, doenças do sistema nervoso; Cap. VII, doenças do olho e anexos; Cap. VIII, doenças do ouvido e da apófise mastoide; Cap. IX, doenças do aparelho circulatório; Cap. X, doenças do aparelho respiratório; Cap. XI, doenças do aparelho digestivo; Cap. XII, doenças da pele e do tecido subcutâneo; Cap. XIII, doenças do sistema osteomuscular e do tecido conjuntivo; Cap. XIV, doenças do aparelho geniturinário; Cap. XVI, algumas afecções originadas no período perinatal; Cap. XVII, malformações congênitas, deformidades e anomalias cromossômicas; Cap. XVIII, sintomas, sinais e achados anormais em exames clínicos e laboratoriais; Cap. XX, causas externas de morbidade e mortalidade. Fonte: SIM/MS, 2017.

\section{Figura 2 - Número de óbitos registrados no Brasil, segundo as causas (Capítulo CID), 2011 a 2015, sexo feminino.}

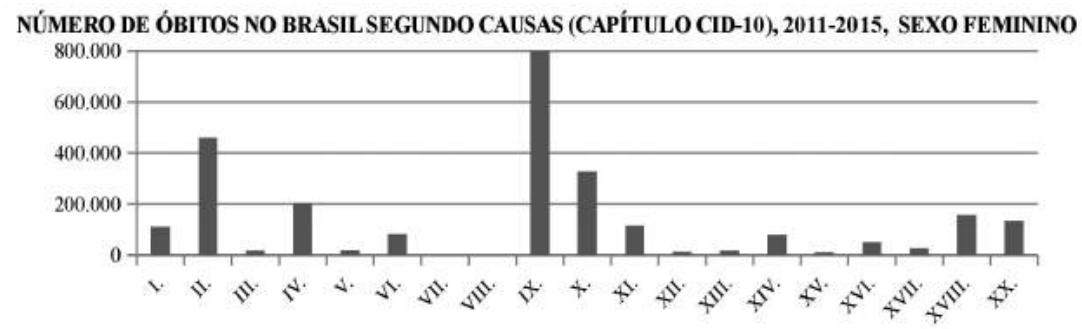

Causas de óbito segundo o Código Internacional de Doenças, CID-10: Capítulo I, algumas doenças infecciosas e parasitárias; Cap. 
II, neoplasias (tumores); Cap. III, doenças do sangue, órgãos hematopoiéticos e transtornos imunitários; Cap. IV, doenças endócrinas nutricionais e metabólicas; Cap. V, transtornos mentais e comportamentais; Cap. VI, doenças do sistema nervoso; Cap. VII, doenças do olho e anexos; Cap. VIII, doenças do ouvido e da apófise mastoide; Cap. IX, doenças do aparelho circulatório; Cap. X, doenças do aparelho respiratório; Cap. XI, doenças do aparelho digestivo; Cap. XII, doenças da pele e do tecido subcutâneo; Cap. XIII, doenças do sistema osteomuscular e do tecido conjuntivo; Cap. XIV, doenças do aparelho geniturinário; Cap. XV, gravidez parto e puerpério; Cap. XVI, algumas afecções originadas no período perinatal; Cap. XVII, malformações congênitas, deformidades e anomalias cromossômicas; Cap. XVIII, sintomas, sinais e achados anormais em exames clínicos e laboratoriais; Cap. XX, causas externas de morbidade e mortalidade. Fonte: SIM/MS, 2017.

Dentre as mortes violentas registradas no país entre 2011 e 2015, as agressões causaram a maior parte dos óbitos masculinos (259.260); seguidas por acidentes de transporte (179.314); outras causas externas de lesões acidentais (98.976); e suicídio (41.331). Dentre as vítimas do sexo feminino, a maioria faleceu em decorrência de outras causas externas de lesões acidentais (43.495); acidentes de transporte (38.992); agressões (23.441); eventos cuja intenção é indeterminada (12.532); e suicídio (11.198) (SIM/MS, 2017).

Em Santa Catarina, entre 2011 e 2015, ao comparar-se os números de óbitos devidos às diferentes causas (capítulo CID-10), verifica-se que as causas externas (capítulo XX) corresponderam à terceira principal causa de óbito dos homens, e à quinta causa de morte entre as mulheres (Figuras 3 e 4), tendo totalizado 21.282 óbitos, sendo 16.873 vítimas do sexo masculino e 4.401 do feminino. Dentre os homens, as principais causas das mortes violentas foram os acidentes de transporte (7.346 mortes), as agressões (3.695), as outras causas externas de lesões acidentais (3.179) e o suicídio (2.205). Entre as mulheres, aquelas também foram as principais causas de óbitos por causas externas (1.827 mortes por acidentes de transporte; 1.275 por outras causas externas de lesões acidentais), sendo que o suicídio resultou em maior número de mortes (655) do que as agressões (488) (SIM/MS, 2017). 
Figura 3 - Número de óbitos em Santa Catarina segundo as causas (Capítulo CID), 2011 a 2015, sexo masculino.

NÚMERO DE ÓBITOS EM SANTA CATARINA SEGUNDO AS CALSAS (CAPÍTULO CID-10), 2011-2015, SEX0 MASCULINO

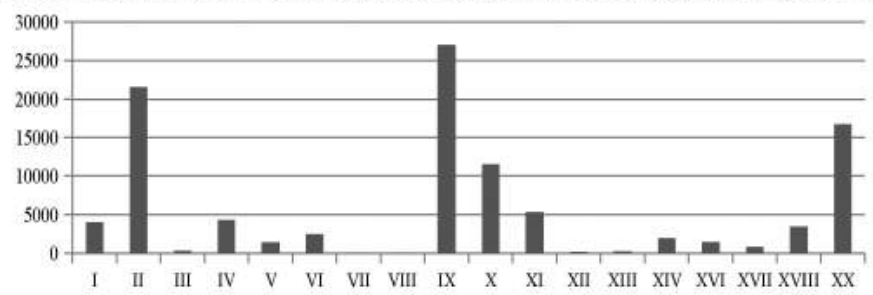

Causas de óbito segundo o Código Internacional de Doenças, CID-10: Capítulo I, algumas doenças infecciosas e parasitárias; Cap. II, neoplasias (tumores); Cap. III, doenças do sangue, órgãos hematopoiéticos e transtornos imunitários; Cap. IV, doenças endócrinas nutricionais e metabólicas; Cap. V, transtornos mentais e comportamentais; Cap. VI, doenças do sistema nervoso; Cap. VII, doenças do olho e anexos; Cap. VIII, doenças do ouvido e da apófise mastoide; Cap. IX, doenças do aparelho circulatório; Cap. X, doenças do aparelho respiratório; Cap. XI, doenças do aparelho digestivo; Cap. XII, doenças da pele e do tecido subcutâneo; Cap. XIII, doenças do sistema osteomuscular e do tecido conjuntivo; Cap. XIV, doenças do aparelho geniturinário; Cap. XVI, algumas afecções originadas no período perinatal; Cap. XVII, malformações congênitas, deformidades e anomalias cromossômicas; Cap. XVIII, sintomas, sinais e achados anormais em exames clínicos e laboratoriais; Cap. XX, causas externas de morbidade e mortalidade. Fonte: SIM/MS, 2017.

\section{Figura 4 - Número de óbitos em Santa Catarina segundo} as causas (Capítulo CID), 2011 a 2015, sexo feminino.

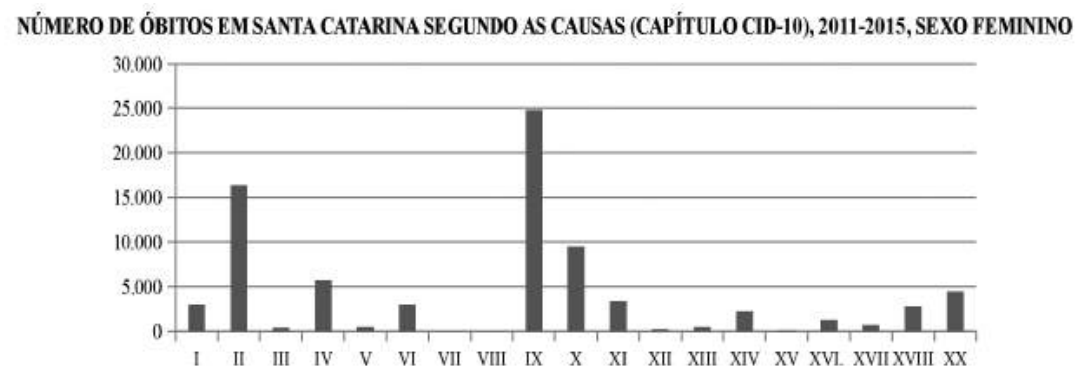


Causas de óbito segundo o Código Internacional de Doenças, CID-10: Capítulo I, algumas doenças infecciosas e parasitárias; Cap. II, neoplasias (tumores); Cap. III, doenças do sangue, órgãos hematopoiéticos e transtornos imunitários; Cap. IV, doenças endócrinas nutricionais e metabólicas; Cap. V, transtornos mentais e comportamentais; Cap. VI, doenças do sistema nervoso; Cap. VII, doenças do olho e anexos; Cap. VIII, doenças do ouvido e da apófise mastoide; Cap. IX, doenças do aparelho circulatório; Cap. X, doenças do aparelho respiratório; Cap. XI, doenças do aparelho digestivo; Cap. XII, doenças da pele e do tecido subcutâneo; Cap. XIII, doenças do sistema osteomuscular e do tecido conjuntivo; Cap. XIV, doenças do aparelho geniturinário; Cap. XV, gravidez parto e puerpério; Cap. XVI, algumas afecções originadas no período perinatal; Cap. XVII, malformações congênitas, deformidades e anomalias cromossômicas; Cap. XVIII, sintomas, sinais e achados anormais em exames clínicos e laboratoriais; Cap. XX, causas externas de morbidade e mortalidade. Fonte: SIM/MS, 2017.

\section{A mortalidade por causas violentas nas microrre- giões de Santa Catarina}

\subsection{Introdução}

Na Tabela 1 são listados os municípios de Santa Catarina em cada microrregião definida pelo IBGE e, na Tabela 2, são apresentados os números de óbitos registrados segundo local de ocorrência nas microrregiões de Santa Catarina, no período de 2011 a 2015, decorrentes de suicídio, agressões, e acidentes de transporte, para os sexos masculino e feminino. 


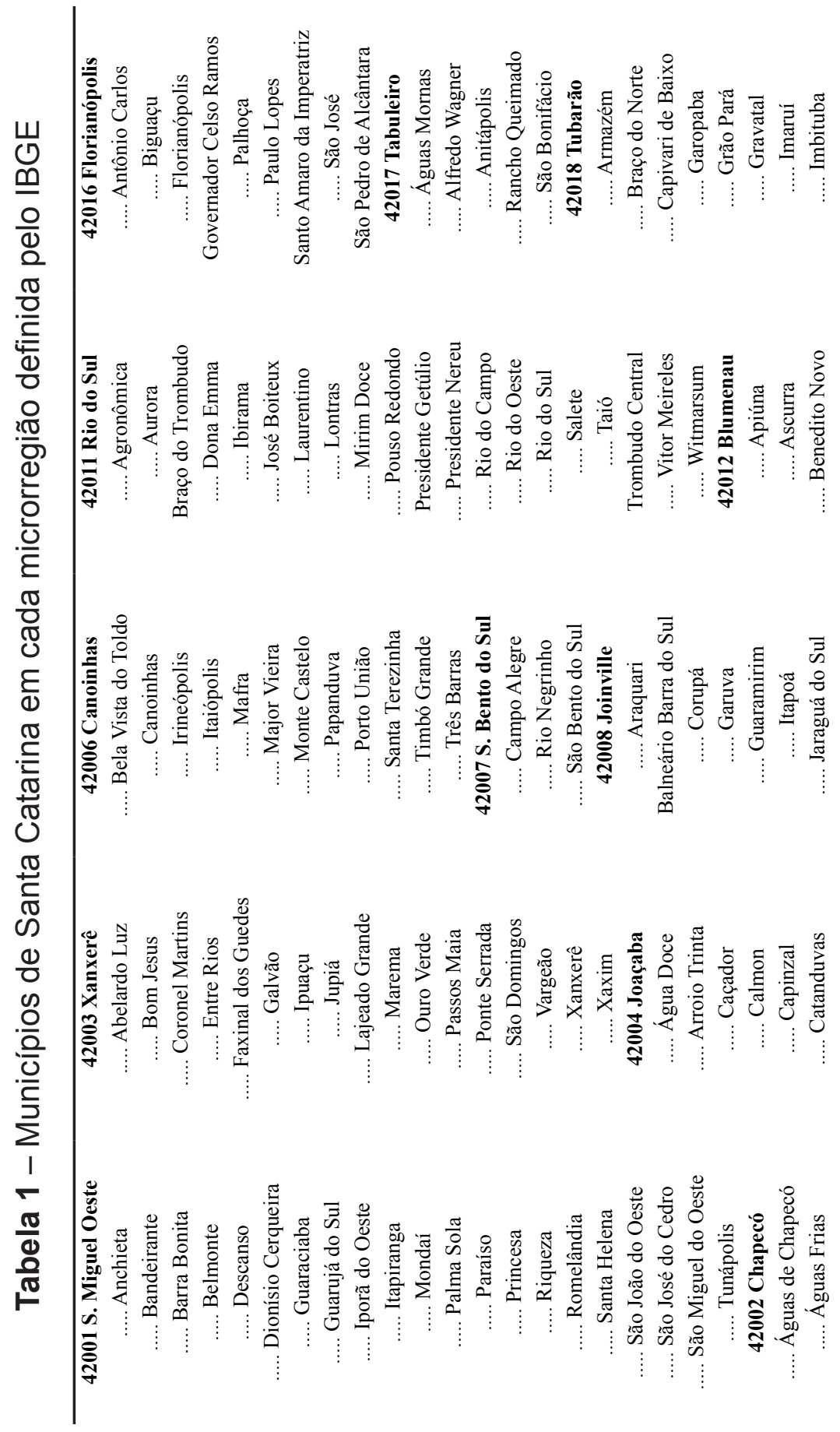




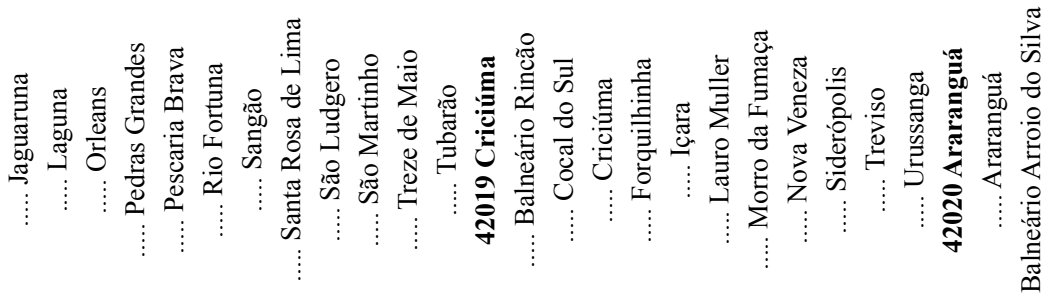

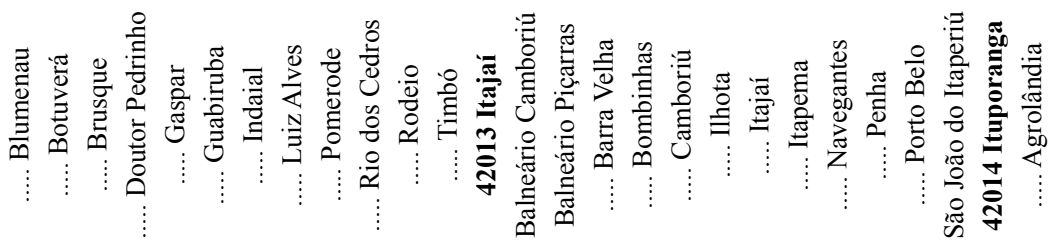

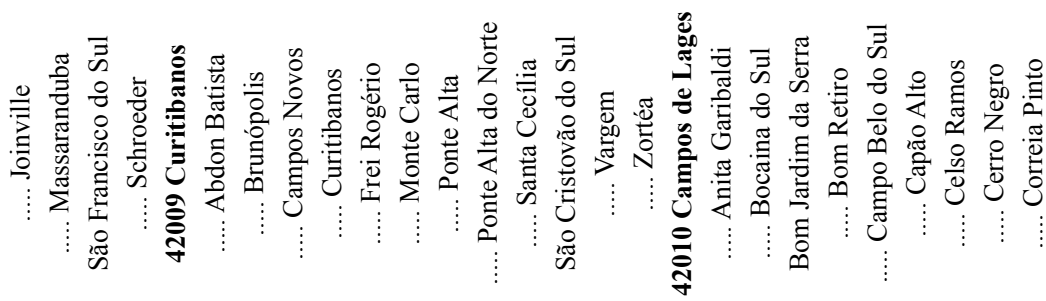

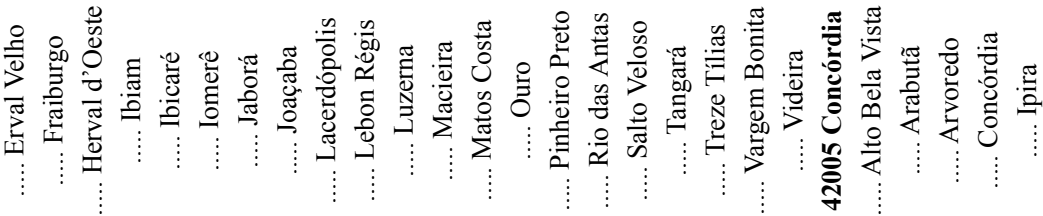

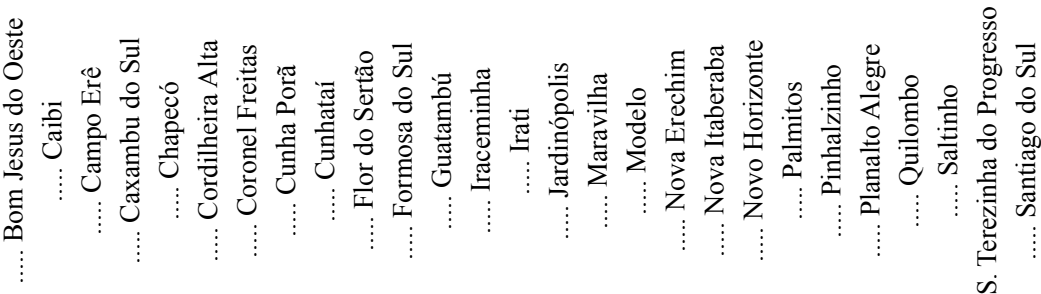




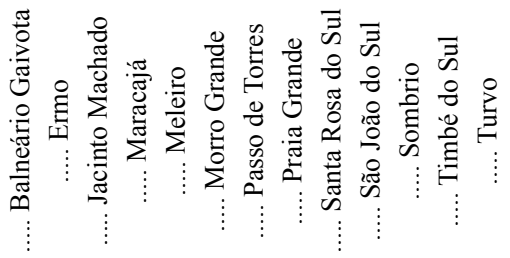

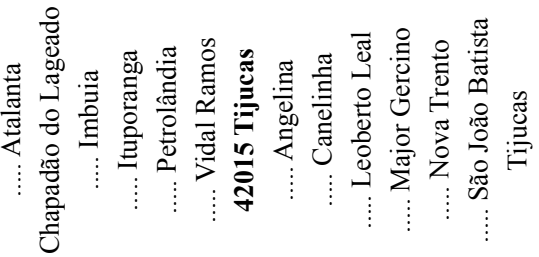

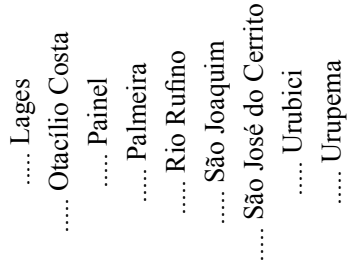

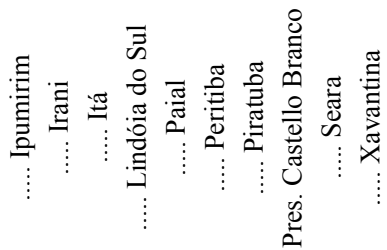

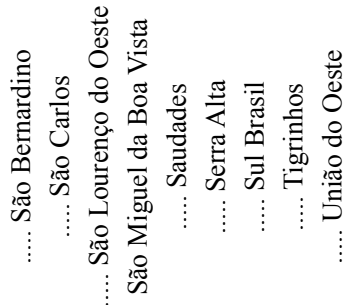

을 


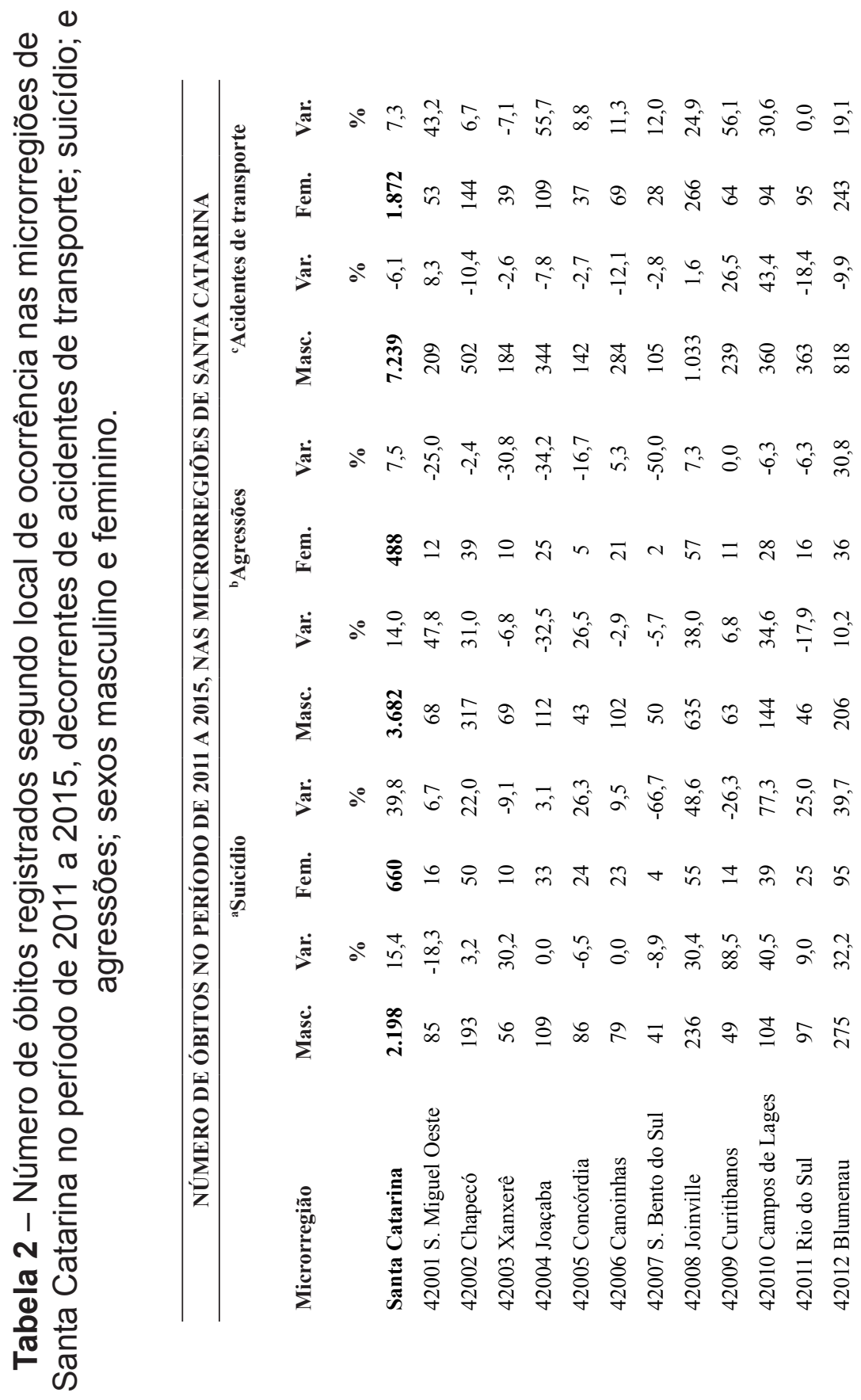




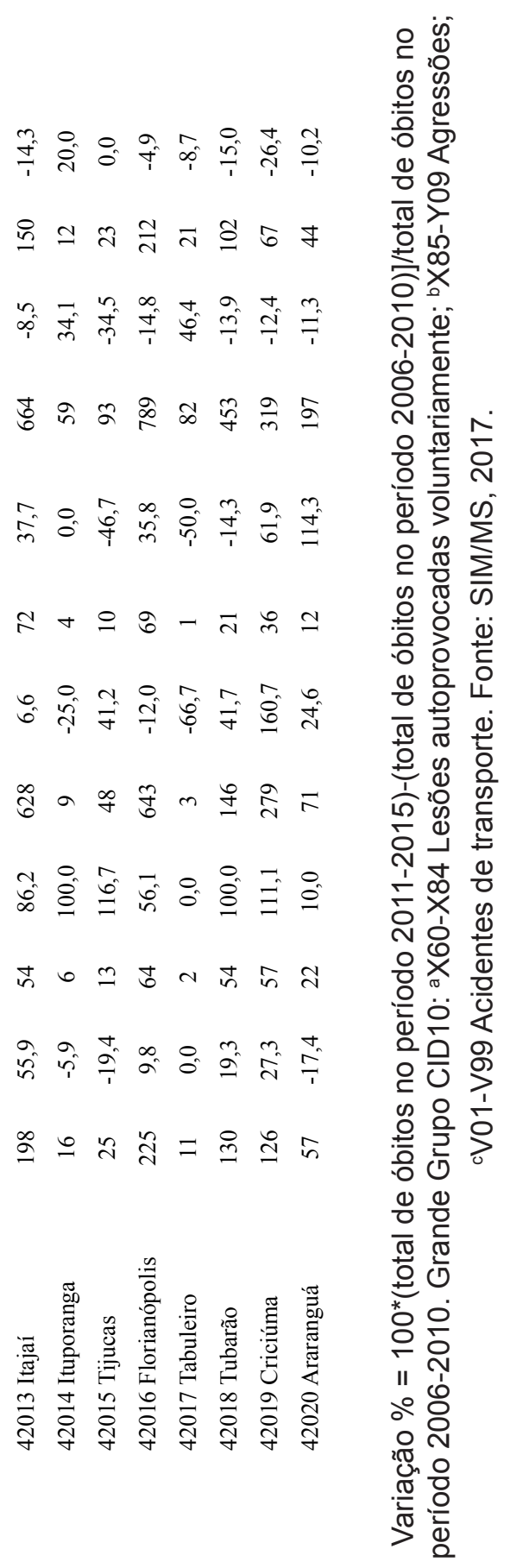




\subsection{A mortalidade por suicídio}

Com relação ao suicídio (valores calculados a partir de dados do SIM/MS, 2017), para o sexo masculino, as taxas de mortalidade a cada 100 mil habitantes registradas em Santa Catarina no período de 2011 a 2015 foram 59\% maiores do que a do país, enquanto que nas microrregiões de São Miguel D’Oeste, Chapecó, Concórdia e Tabuleiro os índices foram superiores ao dobro do registrado a nível nacional. Em todas as microrregiões do Estado, as taxas de suicídio masculino registradas no período foram superiores à média do país (Figura 5). Para o sexo feminino, as taxas de suicídio registradas em Santa Catarina ultrapassaram em mais de $80 \%$ a média nacional entre 2011 e 2015 . Na microrregião de Concórdia, o índice médio de suicídio foi superior ao triplo do registrado a nível nacional, e nas microrregiões de Chapecó, Curitibanos, Campos de Lages, Rio do Sul, Blumenau, Tijucas, Tubarão, Criciúma e Araranguá, ultrapassou o dobro da média do país. Apenas na microrregião de São Bento do Sul, a taxa média de suicídio ficou abaixo da nacional, naquele período (Figura 6).

Alguns autores classificam a mortalidade por suicídio como baixa (menores que 05 óbitos/100 mil habitantes), média (acima de 05 e menos de 15), alta (acima de 15 e menos de 30) e muito alta (mais de 30), sendo esta última categoria presente em alguns países da Ásia e Europa3. Portanto, os dados descritos indicam que, para o sexo masculino (Figura 5), Santa Catarina apresentou entre 2011 e 2015, taxas globais de suicídio consideradas médias, enquanto que nas microrregiões de Concórdia, São Miguel D’Oeste, Chapecó, Rio do Sul, Tabuleiro, Curitibanos e Blumenau, os índices aferidos no período de 2011 a 2015 foram classificados como altos. Para o sexo feminino, a mortalidade por suicídio em Santa Catarina (Figura 6) ficou no patamar considerado baixo, mas nas microrregiões de Concórdia, Criciúma, Tubarão, Campos de Lages, Tijucas e Blumenau, alcançou índices considerados médios.

3 Diekstra, R. F. W.; Gulbinat, W. The epidemiology of suicidal behaviour: a review of three continents. WId. HIth. Sta. Q., v. 46, p. 52-68, 1993. 
Figura 5 - Taxas médias de mortalidade por 100 mil habitantes por acidentes de transporte, suicídio e agressões, período de 2011 a 2015, sexo masculino, segundo local de ocorrência nas microrregiões de Santa Catarina.

Mortalidade por 100 mil habitantes, 2011 a 2015, sexo masculino

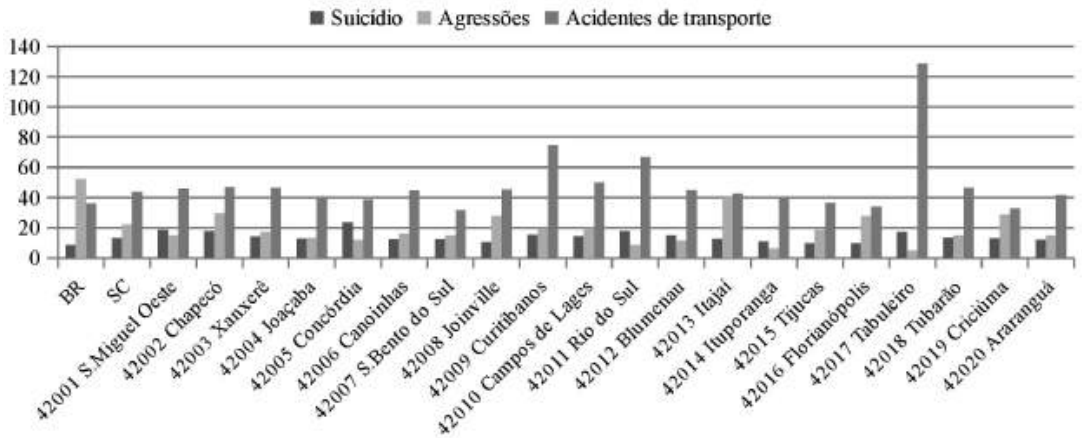

Figura 6 - Taxas médias de mortalidade por 100 mil habitantes por acidentes de transporte, suicídio e agressões, período de 2011 a 2015, sexo feminino, segundo local de ocorrência nas microrregiões de Santa Catarina.

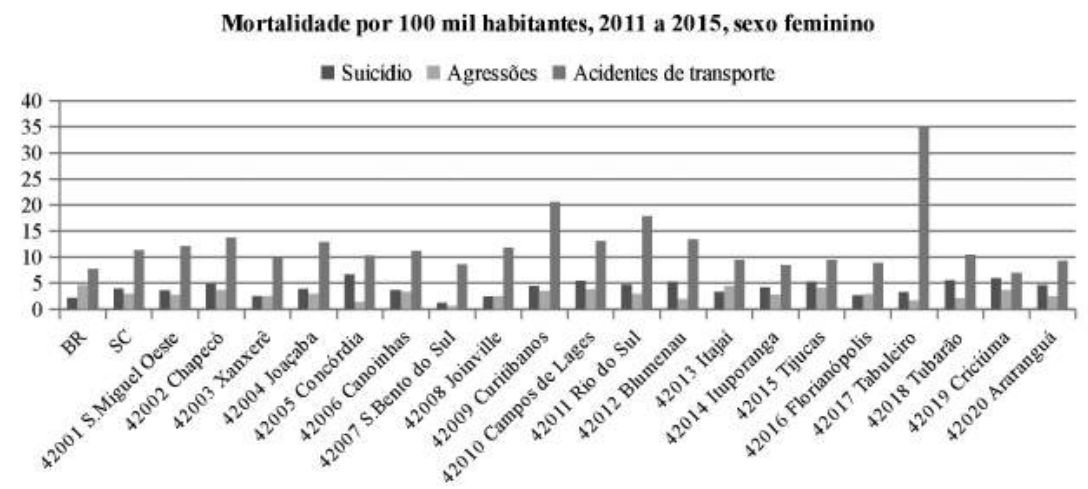

Os dados apresentados na Tabela 2 revelam que, para o sexo masculino, o número de suicídios em Santa Catarina aumentou em 15,4\% no 
período de 2011 a 2015, em comparação com o período de 2006 a 2010. Os maiores aumentos aconteceram nas microrregiões de Curitibanos $(88,5 \%) \mathrm{e}$ Itajaí (55,9\%), enquanto que nas microrregiões de Xanxerê, Joinville, Campos de Lages e Blumenau, ultrapassaram 30\% de incremento entre aqueles dois períodos de cinco anos. Para o sexo feminino, houve 39,8\% de aumento no número de suicídios em Santa Catarina, no período de 2011 a 2015, em comparação com o período de 2006 a 2010. Notavelmente, nas microrregiões de Ituporanga, Tijucas, Tubarão e Criciúma, os números mais do que dobraram e, na microrregião de Itajaí, aumentaram em 86,2\% (Tabela 2).

\subsection{A mortalidade por agressões}

As taxas de mortalidade por agressões registradas entre 2011 e 2015, para o sexo masculino, ficaram abaixo da média nacional em Santa Catarina em todas as suas microrregiões, tendo ultrapassado $50 \%$ do valor nacional apenas em Chapecó, Joinville, Itajaí, Florianópolis e Criciúma (Figura 5). Para o sexo feminino, as taxas de mortalidade por agressões também ficaram abaixo da média nacional no Estado e em todas as suas microrregiões, tendo alcançado média abaixo da metade do valor do país nas microrregiões de Concórdia, São Bento do Sul e Tabuleiro (Figura 6). As microrregiões de Santa Catarina onde os índices de mortalidade de mulheres vítimas de agressões ultrapassaram a taxa do Estado entre $2011 \mathrm{e}$ 2015 foram, em ordem decrescente, Itajaí, Tijucas, Campos de Lages, Criciúma, Chapecó, Curitibanos, Canoinhas, Rio do Sul e Joaçaba (Figura 6).

Os índices apresentados na Tabela 2 demonstram que, no período de 2011 a 2015, em comparação com o período de 2006 a 2010, houve um aumento de $14 \%$ no número de óbitos por agressões em Santa Catarina, para o sexo masculino. Na microrregião de Criciúma o aumento foi de 160,7\%, enquanto que nas microrregiões de São Miguel D’Oeste, Chapecó, Joinville, Campos de Lages, Tijucas e Tubarão, foi superior a 30\%. Para o sexo feminino, as agressões vitimaram 7,5\% a mais de mulheres no período de 2011 a 2015 do que entre 2006 e 2010. Na microrregião de Araranguá, o aumento foi de $114,3 \%$ e, de Criciúma, 61,9\%. Nas microrregiões de Blumenau, Itajaí e Florianópolis os incrementos ultrapassaram 30\% (Tabela 2).

\subsection{A mortalidade por acidentes de transporte}

As taxas de mortalidade por acidentes de transporte a cada $100 \mathrm{mil}$ habitantes calculadas para o período de 2011 a 2015 revelam que, para o 
sexo masculino, a taxa média do Estado de Santa Catarina ficou 20,6\% acima da registrada no país, e apenas as microrregiões de São Bento do Sul, Florianópolis e Criciúma apresentaram índices abaixo da média nacional. As microrregiões de Tabuleiro, Curitibanos, Rio do Sul, Campos de Lages, Chapecó, Tubarão, Xanxerê, São Miguel D’Oeste, Joinville, Blumenau e Canoinhas, em ordem decrescente, apresentaram índices de mortalidade por acidentes de transporte, para o sexo masculino, acima do registrado em Santa Catarina (Figura 5). Naquele mesmo período, para o sexo feminino, a taxa média de mortalidade por acidentes de transporte no Estado ultrapassou a nacional em $48 \%$, e o índice estadual foi superado nas microrregiões de Tabuleiro, Curitibanos, Rio do Sul, Chapecó, Blumenau, Campos de Lages, Joaçaba, São Miguel D’Oeste e Joinville. Apenas a microrregião de Criciúma apresentou índice inferior ao do país, naquele período (Figura 6).

Nos Estados Unidos, em 2014, foi aferida a taxa de mortalidade por acidentes de transporte em 10,6 óbitos por 100 mil habitantes4, índice este que foi ultrapassado entre 2011 e 2015 no Estado de Santa Catarina e em todas as suas microrregiões, para o sexo masculino (Figura 5); e para o sexo feminino, no Estado e nas microrregiões de São Miguel D’Oeste, Chapecó, Joaçaba, Canoinhas, Joinville, Curitibanos, Campos de Lages, Rio do Sul, Blumenau e Tabuleiro (Figura 6).

Em Santa Catarina, o número de óbitos do sexo masculino decorrentes de acidentes de transporte, diminuiu em $6,1 \%$ no período de 2011 a 2015, em comparação com o período de 2006 a 2010. Nas microrregiões, entretanto, as mortes aumentaram em mais de $20 \%$ em Curitibanos, Campos de Lages, Ituporanga e Tabuleiro. Para o sexo feminino, por outro lado, as mortes aumentaram em 7,3\%, no Estado. Nas microrregiões de São Miguel D’Oeste, Joaçaba e Curitibanos, o aumento foi superior a $40 \%$, enquanto que ultrapassou $20 \%$ nas microrregiões de Joinville, Campos de Lages e Ituporanga (Tabela 2).

Na Tabela 3 são apresentados os números de óbitos registrados segundo local de ocorrência nas microrregiões de Santa Catarina no período de 2011 a 2015, decorrentes de acidentes de transporte, para os sexos masculino e feminino, segundo os grupos CID-10: motociclista traumatizado em um acidente de transporte; ocupante de automóvel traumatizado em acidente transporte; e pedestre traumatizado em um

$4 \quad$ National Center for Health Statistics - NCHS. Motorvehicle traffic deaths. 2014. Disponível em: <https://www.cdc.gov/nchs/fastats/accidental-injury.htm>. Acesso em: set. 2017. 
acidente de transporte (atropelamento). A maioria das vítimas do sexo masculino, no Estado, ocupavam motocicletas (2.487), enquanto que os ocupantes de automóveis totalizaram 2.169 óbitos e os pedestres atropelados, 960. Entre as mulheres, a maioria das vítimas de acidentes era ocupante de automóveis (784), em segundo lugar foram vítimas de atropelamento (393) e, em terceiro, ocupantes de motocicletas (341) (Tabela 3).

Na Tabela 3 e na Figura 7 os dados revelam que, para o sexo masculino, nas microrregiões de Joinville, Blumenau, Itajaí, Tijucas, Florianópolis, Tubarão, Criciúma e Araranguá a maioria das vítimas de acidentes de transporte eram ocupantes de motocicletas, enquanto que nas demais microrregiões do Estado, os ocupantes de automóveis foram a maioria. Para o sexo feminino, a maior parte das vítimas de acidentes de transporte nas microrregiões de Santa Catarina ocupava automóveis, exceto em Itajaí, onde a maioria das vítimas ocupava motocicletas, e em Florianópolis, onde as pedestres foram a maioria das vítimas (Tabela 3 e Figura 8).

Em Santa Catarina, o número de óbitos de ocupantes de motocicletas, do sexo masculino, aumentou em $8,1 \%$ no período de 2011 a 2015, em comparação com o período de 2006 a 2010. Notavelmente, as mortes de motociclistas aumentaram mais de $120 \%$ nas microrregiões de São Miguel D'Oeste, Campos de Lages e Tabuleiro, e mais de $40 \%$ nas microrregiões de Chapecó, Xanxerê e Ituporanga. Ainda para o sexo masculino, os óbitos de ocupantes de automóveis aumentaram $22 \%$ no Estado e mais de 60\% nas microrregiões de São Miguel D'Oeste, Curitibanos, Tijucas e Tabuleiro, enquanto que o número de vítimas de atropelamento diminui no Estado e em todas as suas microrregiões, exceto em Campos de Lages e Araranguá. Entre as mulheres, em Santa Catarina o número de vítimas ocupantes de motocicletas diminuiu em $16 \%$, mas aumentou mais de 50\% nas microrregiões de Xanxerê e de São Bento do Sul. Os óbitos de ocupantes de automóveis, por outro lado, aumentaram em 56,2\% no Estado e em 400,0\% em Ituporanga, 233,3\% em Tijucas, e em mais de $100 \%$ nas microrregiões de São Miguel D'Oeste, Joaçaba, Curitibanos, Blumenau, Ituporanga (400,0\%), Tijucas (233,3\%), Florianópolis e Tabuleiro. No Estado e na maioria das microrregiões, diminuiu o número de mulheres vitimadas por atropelamento, mas estes aumentaram em mais de $100 \%$ nas microrregiões de Concórdia, Campos de Lages e Tabuleiro e Araranguá no período de 2011 a 2015, em comparação com o período de 2006 a 2010 (Tabela 3). 


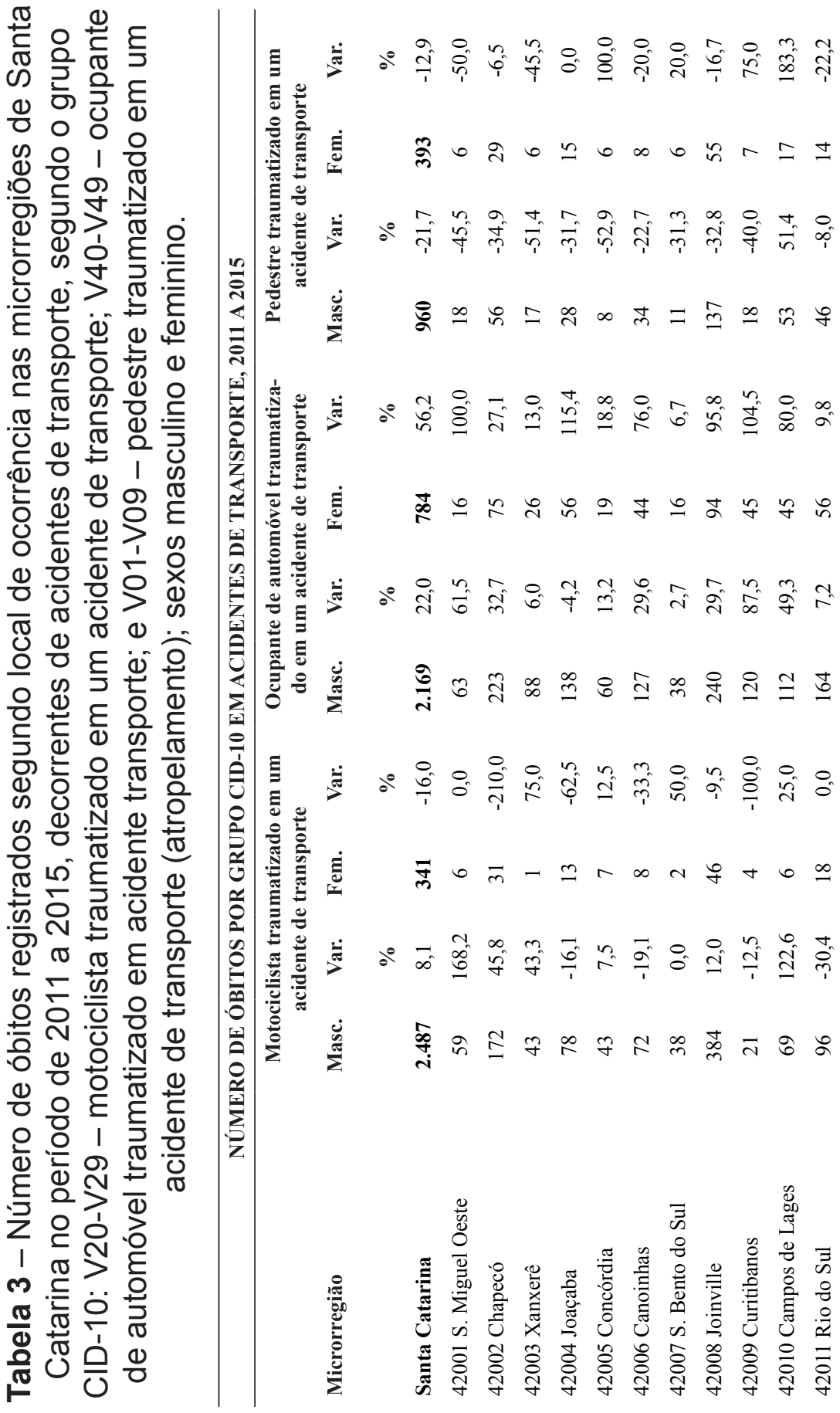




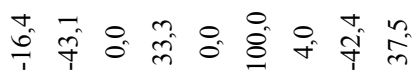

๓

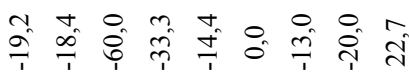

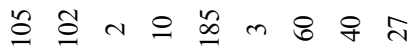

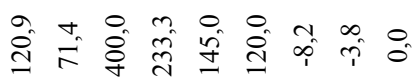

n๐

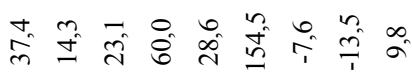

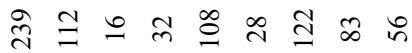

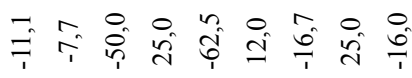

8 भ $m$ ले

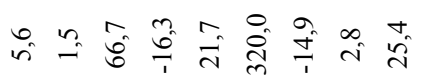

$\bar{ర}$

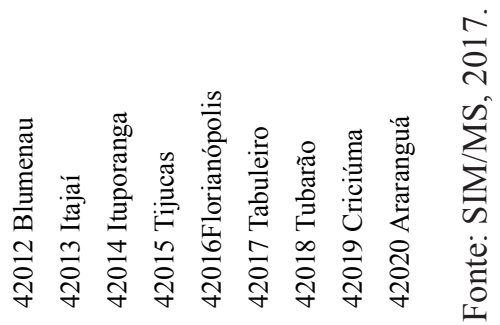


Figura 7 - Número de óbitos registrados segundo local de ocorrência nas microrregiões de Santa Catarina no período de 2011 a 2015, decorrentes de acidentes de transporte, segundo o grupo CID-10: V20-V29 - motociclista traumatizado em um acidente de transporte; V40-V49 - ocupante de automóvel traumatizado em acidente transporte; e V01-V09 - pedestre traumatizado em um acidente de transporte (atropelamento); sexo masculino.

NÚMERO DE ÓBITOS POR GRUPO CID-10 EM ACIDENTES DE TRANSPORTE, 2011 A 2015, SEXO MASCULINO

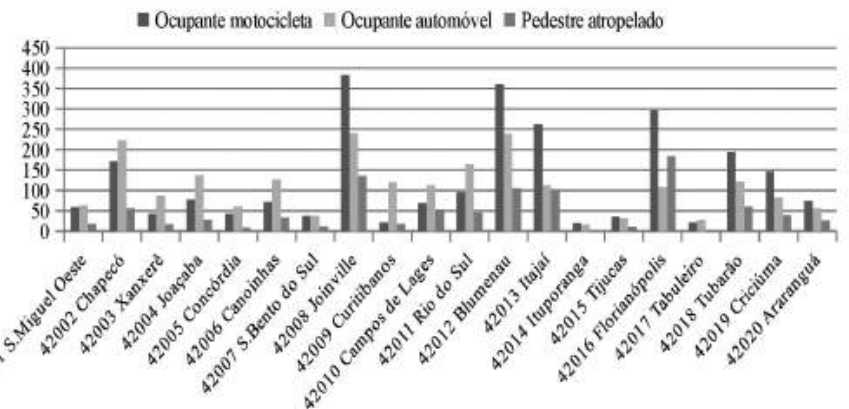

SIM/MS, 2017.

Figura 8-Número de óbitos registrados segundo local de ocorrência nas microrregiões de Santa Catarina no período de 2011 a 2015, decorrentes de acidentes de transporte, segundo o grupo CID-10: V20-V29 - motociclista traumatizado em um acidente de transporte; V40-V49-ocupante de automóvel traumatizado em acidente transporte; e V01-V09- pedestre traumatizado em um acidente de transporte (atropelamento); sexo feminino.

NÚMERO DE ÓBITOS POR GRUPO CID-10 EM ACIDENTES DE TRANSPORTE

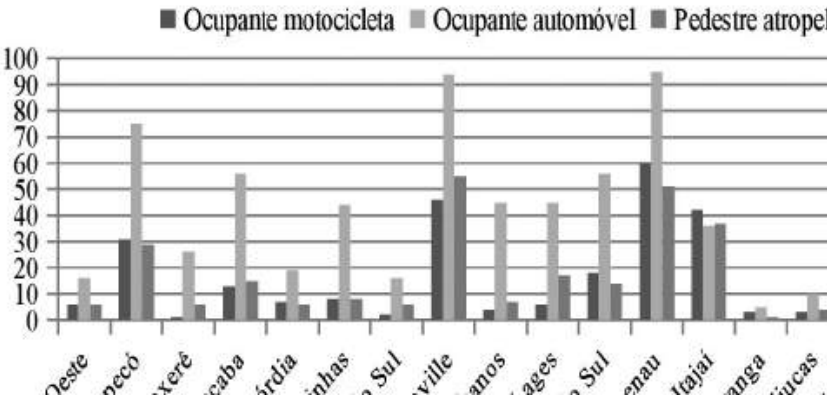

SIM/MS, 2017. 


\section{Conclusões}

Os dados apresentados no presente artigo revelam que a violência tem resultado em milhares de óbitos, tanto no Brasil, quanto no Estado de Santa Catarina.

Para o sexo masculino, Santa Catarina apresentou entre 2011 e 2015 taxas globais de suicídio consideradas médias, enquanto que nas microrregiões de Concórdia, São Miguel D’Oeste, Chapecó, Rio do Sul, Tabuleiro, Curitibanos e Blumenau, os índices aferidos foram classificados como altos. Para o sexo feminino, a mortalidade por suicídio no Estado ficou no patamar considerado baixo, mas nas microrregiões de Concórdia, Criciúma, Tubarão, Campos de Lages, Tijucas e Blumenau, alcançou índices considerados médios. Quanto à evolução do número de suicídios no Estado, no período de 2011 a 2015 em comparação com os cinco anos de 2006 a 2010: o número de suicídios de homens aumentou em $15,4 \%$ e o de mulheres, em $39,8 \%$. Nas microrregiões, os dados revelaram que Xanxerê, Joinville, Curitibanos, Campos de Lages, Blumenau e Itajaí, apresentaram incremento do número de suicídios de homens em mais de $30 \%$, enquanto que o de mulheres teve incremento de mais de 100\% em Ituporanga, Tijucas, Tubarão e Criciúma, e de e mais de 50\% em Campos de Lages, Itajaí e Florianópolis.

As taxas de mortalidade por agressões registradas entre $2011 \mathrm{e}$ 2015, para o sexo masculino, ficaram abaixo da média nacional em Santa Catarina em todas as suas microrregiões, tendo ultrapassado $50 \%$ do valor nacional apenas em Chapecó, Joinville, Itajaí, Florianópolis e Criciúma. Para o sexo feminino, as taxas de mortalidade por agressões também ficaram abaixo da média nacional no Estado e em todas as suas microrregiões, enquanto que nas microrregiões de Itajaí, Tijucas, Campos de Lages, Criciúma, Chapecó, Curitibanos, Canoinhas, Rio do Sul e Joaçaba os índices de mortalidade de mulheres vítimas de agressões ultrapassaram a taxa do Estado, naquele período. Comparando-se os dois períodos de cinco anos, de 2011 a 2015 com 2006 a 2010, o número de óbitos masculinos decorrentes de agressões aumentou em 14,0\% no Estado, e os femininos, em 7,5\%. Nas microrregiões, comparando-se aqueles dois períodos de cinco anos, os maiores incrementos dos óbitos por agressões, para o sexo masculino, aconteceram em Criciúma (160,7\%), São Miguel do Oeste (47,8\%), Tubarão (41,7\%), Tijucas (41,2\%), Joinville (38,0\%), Campos de Lages $(34,6 \%)$ e Chapecó $(31,0 \%)$. Para o sexo feminino, os maiores aumentos foram aferidos em Araranguá (114,3\%), Criciúma (61,9\%), Itajaí (37,7\%), Florianópolis $(35,8 \%)$ e Blumenau $(30,8 \%)$. Em outras microrregiões do Estado, o número de óbitos por agressões diminuiu entre aqueles dois períodos, para ambos os sexos.

As taxas de mortalidade por acidentes de transporte a cada 100 mil habitantes calculadas para o período de 2011 a 2015 revelam que, para o sexo 
masculino, a taxa média do Estado de Santa Catarina ficou 20,6\% acima da registrada no país, e as microrregiões de Tabuleiro, Curitibanos, Rio do Sul, Campos de Lages, Chapecó, Tubarão, Xanxerê, São Miguel D’Oeste, Joinville, Blumenau e Canoinhas, em ordem decrescente, apresentaram índices de mortalidade por acidentes de transporte, para o sexo masculino, acima do registrado no Estado. Naquele mesmo período, para o sexo feminino, a taxa média de mortalidade por acidentes de transporte no Estado ultrapassou a nacional em $48 \%$, e o índice estadual foi superado nas microrregiões de Tabuleiro, Curitibanos, Rio do Sul, Chapecó, Blumenau, Campos de Lages, Joaçaba, São Miguel D’Oeste e Joinville. Os índices de mortalidade por acidentes de transporte aferidos para o sexo masculino ultrapassaram os medidos nos Estados Unidos em 2014, tanto no Estado, quanto em todas as microrregiões de Santa Catarina; para o sexo feminino, o mesmo ocorreu no Estado e nas microrregiões de São Miguel D’Oeste, Chapecó, Joaçaba, Canoinhas, Joinville, Curitibanos, Campos de Lages, Rio do Sul, Blumenau e Tabuleiro.

No Estado, o número de óbitos do sexo masculino por acidentes de transporte diminuiu em 6,1\% no período de 2011 a 2015, em comparação com o período de 2006 a 2010. Nas microrregiões, entretanto, as mortes aumentaram em mais de $20 \%$ em Curitibanos, Campos de Lages, Ituporanga e Tabuleiro. Para o sexo feminino, por outro lado, as mortes aumentaram em 7,3\% no Estado, no período de 2011 a 2015, em comparação com o período de 2006 a 2010. Nas microrregiões de São Miguel D'Oeste, Joaçaba e Curitibanos, o aumento foi superior a $40 \%$, enquanto que ultrapassou $20 \%$ nas microrregiões de Joinville, Campos de Lages e Ituporanga.

No Estado de Santa Catarina, entre 2011 e 2015, a maioria das vítimas de acidentes de transporte, do sexo masculino, ocupavam motocicletas (2.487), enquanto que os ocupantes de automóveis totalizaram 2.169 óbitos, e os pedestres atropelados, 960. Nas microrregiões de Joinville, Blumenau, Itajaí, Tijucas, Florianópolis, Tubarão, Criciúma e Araranguá a maioria das vítimas de acidentes de transporte eram ocupantes de motocicletas, enquanto que os ocupantes de automóveis foram a maioria das vítimas de acidentes nas demais microrregiões do Estado. Entre as mulheres, a maioria das vítimas de acidentes era ocupante de automóveis (784), em segundo lugar, vítimas de atropelamento (393) e, em terceiro, as ocupantes de motocicletas (341). Nas microrregiões de Santa Catarina, a maioria das mulheres vítimas de acidentes ocupava automóveis, exceto em Itajaí, onde a maioria ocupava motocicletas e em Florianópolis, onde as pedestres foram a maioria das vítimas.

No Estado, o número de óbitos de ocupantes de motocicletas do sexo masculino aumentou em 8,1\% no período de 2011 a 2015, em comparação com o período de 2006 a 2010. Notavelmente, as mortes de motociclistas aumentaram mais de 120\% nas microrregiões de São Miguel D'Oeste, Campos de Lages e Tabuleiro, e mais de 40\% nas microrregiões de Chapecó, 
Xanxerê e Ituporanga. Ainda para o sexo masculino, os óbitos de ocupantes de automóveis aumentaram $22 \%$ no Estado e mais de $60 \%$ nas microrregiões de São Miguel D'Oeste, Curitibanos, Tijucas e Tabuleiro, enquanto que o número de vítimas de atropelamento diminuiu no Estado e em todas as suas microrregiões, exceto em Campos de Lages e Araranguá. Entre as mulheres, em Santa Catarina o número de vítimas ocupantes de motocicletas diminuiu em 16\%, mas aumentou mais de 50\% nas microrregiões de Xanxerê e de São Bento do Sul. Os óbitos de ocupantes de automóveis, por outro lado, aumentaram em 56,2\% no Estado e em 400,0\% em Ituporanga, 233,3\% em Tijucas, e em mais de 100\% nas microrregiões de São Miguel D’Oeste, Joaçaba, Curitibanos, Blumenau, Florianópolis e Tabuleiro. No Estado e na maioria das microrregiões diminuiu o número de mulheres vitimadas por atropelamento, mas estes aumentaram em mais de $100 \%$ nas microrregiões de Concórdia, Campos de Lages e Tabuleiro e Araranguá no período de 2011 a 2015, em comparação com o período de 2006 a 2010.

Os dados apresentados, portanto, devem ser amplamente divulgados aos diferentes setores da sociedade, para que sirvam de alerta e de parâmetro orientador na busca por soluções que resultem na minimização dos números de óbitos por causas violentas no Estado e nas microrregiões de Santa Catarina.

\section{Referências}

BRASIL. MINISTÉRIO DA SAÚDE. Sistema de informações sobre mortalidade - SIM/MS. Disponível em: <http://tabnet.datasus.gov.br/ cgi/deftohtm.exe?sim/cnv/ext10uf.def>. Acesso em: nov. 2017.

DIEKSTRA, R. F. W.; GULBINAT, W. The epidemiology of suicidal behaviour: a review of three continents. Wld. Hlth. Sta. Q., v. 46, p. 52-68, 1993.

NATIONAL CENTER FOR HEALTH STATISTICS - NCHS. Motorvehicle traffic deaths. 2014. Disponível em: $<$ https://www.cdc.gov/nchs/ fastats/accidental-injury.htm>. Acesso em: set. 2017.

OBERMEYER, Z.; MURRAY, C. J. L.; GAKIDOU, E. Fifty years of violent war deaths from Vietnam to Bosnia: analysis of data from the world health survey programme. British Med. J., v. 336, n. 7.659, p. 1.482-1.486, 2008. 